\title{
Does an Immigrant Background Affect the Indication, Incidence or Outcome of Emergency Cesarean Section? Results of the Prospective Data Collection of 111 Births
}

\section{Beeinflusst ein Migrationshintergrund Indikationsstellung, Häufigkeit oder Outcome bei einer Notsectio? Ergebnisse einer prospektiven Datenerfassung bei 111 Geburten}

\section{(C) (1) (오 $\ominus$}

Authors

Matthias David ${ }^{1}$, Katrin Alexandra Scherer ${ }^{1}$, Wolfgang Henrich², Jürgen Breckenkamp ${ }^{3}$

Affiliations

1 Charité-Universitätsmedizin Berlin, Klinik für Gynäkologie, Campus Virchow-Klinikum, Berlin, Germany

2 Charité-Universitätsmedizin Berlin, Kliniken für Geburtsmedizin, Campus Virchow-Klinikum und Campus Charité Mitte, Berlin, Germany

3 Universität Bielefeld, Fakultät für Gesundheitswissenschaften, AG Epidemiologie und International Public Health, Bielefeld, Germany

Key words

cesarean section, emergency cesarean section, immigrant women, perinatal outcome

\section{Schlüsselwörter}

Sectio caesarea, Notsectio, Migrantinnen, perinatales Outcome

received $\quad 6.11 .2017$

revised $\quad 3.1 .2018$

accepted 3.1.2018

Bibliography

DOI https://doi.org/10.1055/s-0044-100147

Geburtsh Frauenheilk 2018; 78: 167-172 @ Georg Thieme

Verlag KG Stuttgart · New York | ISSN 0016-5751

Correspondence

Prof. Dr. med. Matthias David

Charité Universitätsmedizin Berlin,

Campus Virchow-Klinikum, Klinik für Gynäkologie

Augustenburger Platz 1, 13353 Berlin, Germany

matthias.david@charite.de

Deutsche Version unter:

https://doi.org/10.1055/s-0044-100147

\section{ABSTRACT}

Objectives Does the incidence and/or indication(s) for emergency cesarean section differ if the pregnant woman has an immigrant background (IB)? Does a lack of language proficiency (communication problems) and a low acculturation level result in a longer decision-to-delivery interval ( $D-D$ interval)? Are neonates born to women with IB by emergency cesarean section in a poorer condition post delivery?

Patient cohorts and method Standardized interviews were carried out before or immediately after delivery in three Berlin obstetric hospitals. Questions were asked about the sociodemographic background and care aspects as well as about immigration and level of acculturation. Collected data were linked to information obtained from the expectant mother's antenatal records and to care data and perinatal data routinely recorded by the hospitals. Data was analyzed using regression models which adjusted for age, parity, and socioeconomic status.

Results The total patient population consisted of 7100 women (rate of response: 89.6\%); of these women, 111 required emergency cesarean section ( 50 women without IB, 61 immigrant women). Risk factors such as late first antenatal checkup, gestational diabetes, pregnancy-induced hypertension, fetal macrosomia, smoking, and weight gain were similar in both patient cohorts. The incidence of and indications for emergency cesarean section and the D-D interval were similar for both groups. Limited German language proficiency and low levels of acculturation among immigrant women did not prolong the D-D interval. There were no statistically relevant differences between immigrant and non-immigrant cohorts with regard to adverse neonatal conditions (5-minute Apgar score $\leq 7$, umbilical cord arterial $\mathrm{pH}<7.00$ ) or with regard to immediate transfer of the neonate to a pediatric clinic following emergency cesarean section.

Conclusion The factor "immigrant background" did not affect the indication or obstetric outcome following emergency cesarean section. 


\section{ZUSAMMENFASSUNG}

Fragestellungen Unterscheiden sich Häufigkeit und/oder Indikationsstellung für eine Notsectio in Abhängigkeit davon, ob bei der Schwangeren ein Migrationshintergrund $(\mathrm{MH})$ vorliegt? Führen mangelnde Sprachkompetenz (Kommunikationsprobleme) und niedriger Akkulturationsgrad zu einer längeren Entschluss-Entwicklungs-Zeit (E-E-Zeit)? Ist der postnatale Zustand der Neugeborenen von Frauen mit MH nach Notsectio schlechter?

Patientinnenkollektiv und Methodik Standardisierte Interviews wurden vor oder unmittelbar nach der Geburt in 3 Berliner Geburtskliniken erhoben. Dabei wurden Fragen zu soziodemografischen und Versorgungsaspekten sowie zum Migrations- und Akkulturationsstatus gestellt. Zusätzlich erfolgte eine Datenverknüpfung mit Angaben aus dem Mutterpass und mit Versorgungs- und Perinataldaten der Kliniken. Regressionsmodelle zur Adjustierung für Alter, Parität, sozioökonomischen Status wurden durchgeführt.
Ergebnisse Das Gesamtkollektiv umfasste 7100 Frauen (Rücklaufquote 89,6\%), darunter waren 111 Notsectiones ( 50 bei Frauen ohne MH, 61 bei Migrantinnen). Risikofaktoren wie späte 1. Vorsorgeuntersuchung, Gestationsdiabetes, SIH, fetale Makrosomie, Rauchen, Gewichtszunahme waren in beiden Kollektiven ähnlich verteilt. Notsectiohäufigkeit und -indikationen sowie E-E-Zeit waren in beiden Gruppen ähnlich. Geringe deutsche Sprachkenntnisse oder niedriger Akkulturationsgrad bei den Migrantinnen verlängern die E-E-Zeit nicht. Hinsichtlich eines ungünstigen postnatalen Zustands des Neugeborenen (5-min-Apgar-Wert $\leq 7$, arteriellen Nabelschnur-pH-Wert $<7,00$ ) oder bei der unmittelbar postnatalen Verlegungsrate in eine Kinderklinik nach einer Notsectio zeigten sich im Vergleich Migrantinnen- vs. Nichtmigrantinnenkollektiv keine statistisch relevanten Unterschiede.

Schlussfolgerung Der Faktor „Migrationshintergrund“ hat keine relevante Bedeutung bei der Indikationsstellung und für die geburtshilfliche Ergebnisqualität bei Notsectiones.

\section{Introduction}

Cesarean section can be a life-saving procedure for mother and child, but it is always also associated with risks and should therefore only be carried out if it is indicated for maternal and/or fetal reasons $[1,2]$. The cesarean section rate is considered an important obstetric quality indicator $[3,4]$. Cesarean section (CS) rates may be higher if there is increased demand for CS among pregnant women; on the other hand, a low CS incidence can be interpreted as an indication of obstetric shortages. The total mean CS rate in 2016 was $32.01 \%$ for all of Germany [5] and $27.69 \%$ for Berlin [6].

Emergency cesarean sections are defined as abdominal cesarean sections where the mother and/or the fetus are in acute danger and cesarean section is therefore absolutely indicated [7]. The decision to carry out emergency cesarean section is a complex process which develops in a specific concrete obstetric situation and requires realization and rapid assessment of the risky situation and fast decision-making. Recognizing an acute situation which may be potentially life-threatening is considered one of the most challenging tasks in obstetrics. The interval between the indication for emergency cesarean section and delivery of the infant should be as short as possible. The aim is to achieve a decision-to-delivery (D-D) interval of under 20 minutes [8].

A number of studies have reported that there are differences between immigrant women or women with an immigrant background and local, non-immigrant women regarding important perinatal care parameters such as the rate of cesarean sections. The stress of immigration, the disappearance of existing social networks because of immigration or as a consequence of increased acculturation, a lower social status, less access to healthcare, discrimination in the care system, taken either individually or in combination, can all be potential causes of differences in CS rates and perinatal outcomes of immigrant women (e.g. $[9,10])$.
A systematic review of the literature on international migration and delivery by cesarean section found differences in CS rates between immigrant and non-immigrant women in $60 \%$ of analyzed studies but noted that the data are not sufficient to adequately explain the difference [12]. Commonly reported risk factors for CS in immigrant women are language and communication problems, low socio-economic status, poor maternal health, maternal overweight, cephalopelvic disproportion and inadequate prenatal care, while protective factors include the so-called healthy migrant effect, a preference for vaginal delivery, a healthier lifestyle, and a lower maternal age at first delivery $[9-11,13]$.

From a clinical perspective, the rates of emergency CS should not differ between immigrant and non-immigrant women after adjusting for sociodemographic and predisposing factors.

In the last 20 years, to our knowledge no large studies have been carried out in Germany or in Europe which considered the question, based on prospectively collected data, whether immigration or other sociodemographic factors are associated with emergency cesarean section.

This study aimed to answer the following questions:

1. Did the incidence of and/or indications for emergency cesarean section differ depending on whether the pregnant woman had an immigrant background or not?

2. Does a lack of language proficiency and lower level of acculturation result in a longer D-D interval?

3. Is the postnatal state of the neonate (based on 5-minute Apgar score $\leq 7$ and umbilical cord arterial $\mathrm{pH} \leq 7$, neonatal transfer to a pediatric clinic) born to women with an immigrant background worse after emergency C-section? 


\section{Method}

\section{Patient population}

A subgroup analysis was done of data collected for a study funded by the German Research Foundation on "Perinatal data of immigrant women vs. non-immigrant women in Berlin" (grant no.: DA 1199/2-1) carried out between 2010 and 2013 [14]. Obstetric data was collected from three obstetric hospitals in Berlin (Charité Campus Virchow-Klinikum, Vivantes Klinikum am Urban, Vivantes Klinikum Neukölln). Standardized interviews based on validated questionnaires which were available in several languages were carried out with all women a few hours before giving birth. This primary data was linked to the perinatal data recorded by the hospital and regularly reported to the AQUA Institute $\mathrm{GmbH}$ in Göttingen by all hospitals in Germany as part of quality assurance. This reported data includes all obstetric data on every birth and is entered directly into the computer on the labor ward. However, this data provides only insufficient or imprecise information about sociodemographic and immigration status and the levels of acculturation.

\section{Study questionnaires}

The questionnaires used in the study consisted of 23 questions on sociodemographic aspects, 9 questions on aspects of care and 23 questions on immigration and acculturation were relevant. Immigration status was determined in accordance with the recommendations by Schenk et al. [15], based on information about the respective woman's parents' country of birth and the woman's length of stay in Germany and native language. Women were classified into the following groups: 1st generation immigrant women (who had immigrated themselves), 2nd generation immigrant women (direct descendant of immigrants), and women with a binational background (one parent without and one parent with an experience of immigration). Starting in January 2011, the interviews were carried out by trained project members every day for one year on the labor and postnatal wards of the three abovementioned hospitals. All women who gave birth at one of the three hospitals during the survey period, with delivery occurring from the $24+0$ week of gestation onward (fetus showed vital signs), and who were at least 18 years old at the birth of their infant and permanently resident in Germany were included in the survey. Women who were underage, tourists with no permanent residence in Germany and women who had a termination of pregnancy, miscarriage or stillbirth (death of the fetus confirmed on admission to hospital and before the start of labor) were excluded from the study.

\section{Statistical analysis}

Univariate, bivariate and multivariate analysis was done to assess the impact of immigration and acculturation processes on pregnancy and delivery, using the statistical software SAS 9.4. The level of significance was set as $p<0.05$.

\section{Ethics vote and data protection}

The study was approved by the Ethics Committee of Berlin Charité, Ethics Commission I Charité Campus Mitte (No. EA 1/235/08).
Data protection guidelines (Berlin Data Protection Law) were complied with.

\section{Results}

\section{Total patient population}

A total of 8157 women gave birth during the survey period in one of the three Berlin obstetrical hospitals. Data from 7100 women was available for data analysis, which corresponds to a response rate of $89.6 \%$. The 7100 evaluated births also included the complete records of 111 out of 112 deliveries by emergency cesarean section. This subgroup of surgical births was analyzed separately, and the focus was on comparing outcomes between immigrant and non-immigrant women. Because of the small sample sizes only a few variables were included in the regression models.

\section{Emergency cesarean section cohort}

50 emergency cesarean sections were carried out in women without immigrant background, and 61 emergency C-sections were performed in women with an immigrant background (51 1st generation women, 10 2nd generation women). - Table 1 shows some of the basic data of the total cohort of patients who had emergency $C$-section (sample size $n=111$ ). 1st and 2nd generation immigrant women are compared to non-immigrant women (this also includes women of whom one parent immigrated to Germany). The incidence of emergency C-sections is similar for both investigated cohorts.

\section{Risk factors}

A number of risk factors which could potentially affect the CS rate (few antenatal check-ups, late first antenatal check-up, gestational diabetes, pregnancy-induced hypertension, fetal macrosomia, smoking during pregnancy, weight gain in pregnancy) were analyzed to determine whether there were any differences between the two patient cohorts. No statistically significant differences were found between groups.

\section{Indications for emergency C-section}

- Table 2 lists the five most common indications for emergency C-section. There were no statistically relevant differences.

\section{D-D interval}

A comparison of D-D intervals of emergency $C$-sections for immigrant and non-immigrant women showed that the mean D-D interval was 9.1 minutes for the non-immigrant women group and 9.7 minutes for the immigrant women group (no statistically significant difference; Wilcoxon rank-sum test $p=0.814$ ). The $D-D$ interval of 20 minutes was exceeded in $2 \%$ of cases in the non-immigrant women group and in $4.9 \%$ of cases of the immigrant women group.

\section{Acculturation and immigrant background}

We assumed that a lower proficiency in German and a lower level of acculturation might "prolong" the D-D interval because of problems in communication between the patient and medical staff. - Table 3 shows the results of Poisson regression analysis 
- Table 1 Basic sociodemographic and obstetric data $(n=111)$.

\begin{tabular}{|c|c|c|}
\hline & Non-immigrant women $(n=50)$ & Immigrant women $(n=61)$ \\
\hline Relative frequencies & \multicolumn{2}{|l|}{$\mathrm{n}(\%)$} \\
\hline - emergency C-sections/all births & $50 / 3331(1.5 \%)$ & $61 / 3767(1.6 \%)$ \\
\hline - secondary C-sections/all births & $802 / 3331(24.1 \%)$ & $687 / 3767(18.2 \%)$ \\
\hline - emergency C-sections/all secondary C-sections & $50 / 802(6.2 \%)$ & $61 / 687(8.9 \%)$ \\
\hline Age groups & \multicolumn{2}{|l|}{$\mathrm{n}(\%)$} \\
\hline - 18-24 years & $10(20.0 \%)$ & $12(19.7 \%)$ \\
\hline - 25-29 years & $11(22.0 \%)$ & $16(26.2 \%)$ \\
\hline - 30-34 years & $13(26.0 \%)$ & $14(23.0 \%)$ \\
\hline - $35+$ years & $16(32.0 \%)$ & $19(31.2 \%)$ \\
\hline Level of formal education & \multicolumn{2}{|l|}{$\mathrm{n}(\%)$} \\
\hline - low & $3(6.0 \%)$ & $15(24.6 \%)$ \\
\hline - medium & $21(42.0 \%)$ & $27(44.3 \%)$ \\
\hline - high & $26(52.0 \%)$ & $19(31.2 \%)$ \\
\hline Parity & \multicolumn{2}{|l|}{$\mathrm{n}(\%)$} \\
\hline - nullipara & $29(58.0 \%)$ & $30(49.2 \%)$ \\
\hline - multipara & $21(42.0 \%)$ & $31(50.8 \%)$ \\
\hline \multicolumn{3}{|l|}{ Week of gestation at delivery } \\
\hline - mean (SD) & $36.0(5.5)$ & $36.9(4.1)$ \\
\hline - median (range) & $39.0(24-41)$ & $38.0(25-42)$ \\
\hline 5-minute Apgar score & \multicolumn{2}{|l|}{$\mathrm{n}(\%)$} \\
\hline$\cdot \leq 7$ & $17(34.0 \%)$ & $20(32.8 \%)$ \\
\hline Umbilical cord arterial pH & \multicolumn{2}{|l|}{$\mathrm{n}(\%)$} \\
\hline.$\leq 7.00$ & $4(8.0 \%)$ & $8(13.1 \%)$ \\
\hline \multicolumn{3}{|l|}{ Birth weight (g) } \\
\hline - mean (SD) & $2694.3(1054.7)$ & $2741.7(885.3)$ \\
\hline - median (range) & $3040(745-4150)$ & $2860(770-5010)$ \\
\hline Self-assessed proficiency in German & \multicolumn{2}{|c|}{$\mathrm{n}(\%)$} \\
\hline - none/limited & & $16(26.2 \%)$ \\
\hline - medium to very good & & $45(73.8 \%)$ \\
\hline Level of acculturation (Frankfurt Acculturation Scale, FRAKK [16]) & \multicolumn{2}{|l|}{$\mathrm{n}(\%)$} \\
\hline - low (FRAKK median value $\leq 59)$ & & $31(50.8 \%)$ \\
\hline - high (FRAKK median value > 59) & & $30(49.2 \%)$ \\
\hline
\end{tabular}

- Table 2 The five most common indications for emergency C-section (multiple answers possible) in the two investigated patient cohorts.

\begin{tabular}{|l|l|r|c|}
\hline & All & Non-immigrant women & Immigrant women \\
\hline Pathological CTG & 74 & 35 & 39 \\
\hline Premature placental separation & 18 & 10 & 8 \\
\hline Premature birth & 13 & 8 & 5 \\
\hline Previous C-section/uterine surgery & 13 & 8 & 5 \\
\hline Multiple pregnancy & 10 & 5 & 5 \\
\hline
\end{tabular}


- Table 3 Relative risk for a longer D-D interval as a function of proficiency in German and level of acculturation (results of Poisson regression models).

\begin{tabular}{|c|c|c|c|}
\hline & Relative risk & $95 \%$ confidence interval & p-value \\
\hline \multicolumn{4}{|c|}{ Relative risk of longer D-D interval and proficiency in German } \\
\hline Immigrant women (ref.: non-immigrant) & 1.17 & $0.89-1.54$ & 0.2574 \\
\hline 25-29 years (ref.: $18-24$ years) & 1.08 & $0.86-1.36$ & 0.5107 \\
\hline $30-34$ years (ref.: $18-24$ years) & 1.44 & $1.06-1.96$ & 0.0197 \\
\hline $35+$ years (ref.: $18-24$ years) & 1.15 & $0.81-1.63$ & 0.4436 \\
\hline $\begin{array}{l}\text { Proficiency in German, none - limited } \\
\text { (ref: proficiency in German: medium - very good) }\end{array}$ & 0.66 & $0.48-0.90$ & 0.0100 \\
\hline \multicolumn{4}{|l|}{ Relative risk of longer D-D interval and acculturation } \\
\hline Immigrant women (ref.: non-immigrant) & 1.16 & $0.91-1.48$ & 0.2461 \\
\hline $25-29$ years (ref.: $18-24$ years) & 1.03 & $0.81-1.31$ & 0.7819 \\
\hline 30-34 years (ref.: $18-24$ years) & 1.41 & $1.02-1.93$ & 0.0356 \\
\hline $35+$ years (ref.: $18-24$ years) & 1.13 & $0.78-1.64$ & 0.5271 \\
\hline Acculturation low (ref.: acculturation high) & 0.86 & $0.58-1.26$ & 0.4370 \\
\hline
\end{tabular}

of this issue. It appears that lower levels of language proficiency tended to reduce the risk of a longer D-D interval, whereas the level of acculturation (high vs. low) had no effect on the risk of a longer D-D interval.

The study also aimed to investigate whether having an immigrant background increased the likelihood of an adverse neonatal outcome immediately after birth as characterized by a low 5-minute Apgar score of $\leq 7$, an umbilical cord arterial $\mathrm{pH}$ of $\leq 7.00$ or the need to transfer the neonate delivered by emergency C-section to a pediatric clinic immediately after delivery. There were no statistically significant differences between the immigrant and non-immigrant women cohorts.

\section{Discussion}

In immigration countries detailed knowledge of the impact of immigration, ethnicity, acculturation and other social and structural factors affecting pregnancy and birth are important to ensure that adequate care is available. According to data published by the Federal Statistical Office of Germany in September 2016, 81.4 million people are currently living in the Federal Republic of Germany, of which 17.2 million have an immigrant background (defined as either having immigrated themselves or being directly descended from persons who immigrated to Germany). This currently corresponds to around $21.2 \%$ of the total population in Germany [17].

The $\mathrm{C}$-section rate is considered an important indicator for the assessment of the quality of obstetric care $[3,18]$. At the same time, the current discussion about elective C-sections shows that different medical and non-medical factors can affect the CS rate, at least partly $[19,20]$.

In our total patient population the rate of emergency C-sections was $1.57 \%$ (112 out of 7100 ). The perinatal data of Berlin hospitals can be used for comparison. A data analysis for the years 2002-2015 showed only minor fluctuations over this 15-year pe- riod: the rate of emergency C-sections was between 1 and $1.6 \%$ [6].

Emergency C-sections are rare. When they occur, deficits in care during pregnancy, barriers to accessing the healthcare system in an emergency situation on the labor ward, and cultural and communication problems as well as sociodemographic factors such as age and formal education can negatively affect the incidence of C-sections and decision-making and the further perinatal and postnatal course. How immigration and acculturation factors affect the obstetric outcome parameters for emergency C-sections has not been previously studied in Germany. The findings of our subgroup analysis presented here show that the incidence of emergency C-sections was similar for the investigated groups of immigrant and non-immigrant women of a large cohort of women who gave birth in Berlin. There were no differences in the indications for delivery by $\mathrm{C}$-section and no significant differences in neonatal condition after delivery. A lack of proficiency in German or a low level of acculturation by the women who required emergency $\mathrm{C}$-section had no negative impact.

According to Lagrew et al. [21], most emergency C-sections carried out in low-risk pregnant women become necessary due to obstetric conditions which develop during labor and could not have been anticipated or identified pre-partum. It is important to recognize these dangerous maternal-fetal situations and respond adequately and quickly [21].

There were only a few cases in which a D-D interval of more than 20 minutes was recorded; there was no statistically significant difference in the incidence of these cases between the two investigated cohorts (2\% in the non-immigrant and $4.9 \%$ in the immigrant women cohort). We selected this interval as a threshold value, after Heller et al. [8] carried out logistic regression analysis of the correlation between D-D interval and neonatal outcome after emergency $\mathrm{C}$-section and convincingly demonstrated that neonates born after a maximum D-D interval of 10-20 minutes were less likely to have low 5- and 10-minute Apgar scores 
than neonates born after longer D-D intervals. The authors of that study were able to confirm in a large German birth cohort that the indication for an emergency C-section because of (imminent) fetal asphyxia, a D-D with a threshold value of $\leq 20$ minutes had a protective effect [8].

\section{Strengths and Limitations of the Study}

The strengths of this study are the size of the total patient population evaluated in the overall study, the size of the emergency Csection cohort (as emergency $\mathrm{C}$-sections are rare obstetric events and no precise and detailed prospective data collection is usually done), the prospective, multicenter study design, and the high participation rate. For the first time in a perinatal study carried out in Germany, a questionnaire was used to collect precise data on immigration status and acculturation and analyze it together with "incidence of emergency C-sections", "immigration/acculturation" and "newborn status post delivery". The questionnaire used in the study made it possible to supplement the routinely collected clinical perinatal data with important sociodemographic information.

Possible methodological limitations of the study include the documentation quality of the perinatal data routinely collected by the obstetric hospitals. The significance of the results may also be limited because of the relatively small sizes of the studied groups and the sometime small differences and small incidence. It is possible that differences could become statistically significant if the groups were larger. It should also be noted that results obtained from a large city with a high proportion of immigrants among its population of pregnant women, the experience of providing appropriate care and hospitals providing maximum medical care cannot necessarily be generalized to smaller towns or rural areas with a low percentage of immigrants in their population, longer distances to maternity hospitals and quite different resources in terms of staffing and equipment.

But despite these methodological criticisms, our results appear to be the most valid for immigrant women in Germany.

\section{Conclusion for Clinical Practice}

The sociodemographic factor "immigrant background" appears to have no relevant (negative) effect on indications for emergency C-section or obstetric outcomes of women requiring emergency C-section and their newborn infants.

\section{Conflict of Interest}

The authors declare that they have no conflict of interest.

\section{References}

[1] Deneux-Tharaux C, Carmona E, Bouvier-Colle MH et al. Postpartum maternal mortality and caesarean delivery. Obstet Gynecol 2006; 108: 541-548

[2] Hyde MJ, Mostyn A, Modi N et al. The health implications of birth by caesarean section. Biol Rev 2012; 87: 229-243

[3] Río I, Castelló A, Barona C et al. Caesarean section rates in immigrant and native women in Spain: the importance of geographical origin and type of hospital for delivery. Eur J Public Health 2010; 20: 524-529

[4] Zizza A, Tinelli A, Malvasi A et al. Caesarean section in the world: a new ecological approach. J Prev Med Hyg 2011; 52: 161-173

[5] IQTIQ, Hrsg. Qualitätsreport 2016. Berlin: Eigenverlag; 2017: 129

[6] BQS-Institut, Hrsg. Jahresauswertung 2016 Geburtshilfe. Berlin Gesamt. Berlin: Eigenverlag; 2017

[7] Mölgg A, Jirecek S, Girtler V et al. Maternal and neonatal outcome for singleton and twin pregnancies in emergency cesarean section vs. urgent cesarean section in a retrospective evaluation from 2003-2012. Open Journal of Obstetrics and Gynecology 2014; 4: 881-888

[8] Heller G, Bauer E, Schill S et al. Decision-to-delivery time and perinatal complications in emergency cesarean section. Dtsch Arztebl Int 2017; 114: 589-596. doi:10.3238/arztebl.2017.0589

[9] Gissler M, Alexander S, Macfarlane A et al. Stillbirths and infant deaths among migrants in industrialized countries. Acta Obstet Gynecol Scand 2009; 88: 134-148

[10] Bollini P, Pampallona S, Wanner P et al. Pregnancy outcome of migrant women and integration policy: a systematic review of the international literature. Soc Sci Med 2009; 68: 452-461

[11] Razum O, Reeske A, Spallek J, Hrsg. Gesundheit von Schwangeren und Säuglingen mit Migrationshintergrund. Frankfurt am Main: Peter Lang; 2011

[12] Merry L, Small R, Blondel B et al. International migration and caesarean birth: a systematic review and meta-analysis. BMC Pregnancy Childbirth 2013; $13: 27$

[13] Oberaigner $\mathrm{W}$, Leitner $\mathrm{H}$, Oberaigner $\mathrm{K}$ et al. Migrants and obstetrics in Austria-applying a new questionnaire shows differences in obstetric care and outcome. Wien Klin Wochenschr 2013; 125: 34-40

[14] David M, Borde T, Brenne $S$ et al. Obstetric and perinatal outcomes among immigrant and non-immigrant women in Berlin, Germany. Arch Gynecol Obstet 2018; 297: 313-322

[15] Schenk L, Bau AM, Borde T et al. Mindestindikatorensatz zur Erfassung des Migrationsstatus. Empfehlungen für die epidemiologische Praxis. Bundesgesundheitsbl Gesundheitsforsch Gesundheitsschutz 2006; 9: 853-860

[16] Bongard S, Pogge SF, Arslaner $\mathrm{H}$ et al. Acculturation and cardiovascular reactivity of second-generation Turkish migrants in Germany. J Psychosom Res 2002; 53: 795-803

[17] Statistisches Bundesamt/Destatis. Bevölkerung mit Migrationshintergrund auf Rekordniveau. Online: https://www.destatis.de/DE/Zahlen Fakten/GesellschaftStaat/Bevoelkerung/MigrationIntegration/ MigrationIntegration.html; last access: 05.10.2016

[18] Betrán AP, Merialdi M, Lauer JA et al. Rates of caesarean section: analysis of global, regional and national estimates. Paed Perinatal Epidemiol 2007; 21: 98-113

[19] McCourt C, Weaver J, Statham $\mathrm{H}$ et al. Elective cesarean section and decision making: a critical review of the literature. Birth 2007; 34: 65-79

[20] Lavender T, Hofmeyr G], Neilson JP et al. Caesarean section for non-medical reasons at term. Cochrane Database Syst Rev 2012; (3): CD004660. doi:10.1002/14651858.CD004660.pub3

[21] Lagrew DC, Bush MC, McKeown AM et al. Emergent (crash) cesarean delivery: indications and outcomes. Am J Obstet Gynecol 2006; 194: 16381643 